\title{
Class A PBPs have a distinct and unique role in the construction of the pneumococcal cell wall
}

\author{
Daniel Straume ${ }^{a, 1}$, Katarzyna Wiaroslawa Piechowiak ${ }^{a, 1}$, Silje Olsen ${ }^{a}$, Gro Anita Stamsås ${ }^{a}$, Kari Helene Berg ${ }^{a}$,

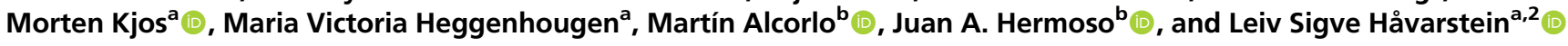 \\ ${ }^{\mathrm{a}}$ Faculty of Chemistry, Biotechnology and Food Science, Norwegian University of Life Sciences, 1432 Ås, Norway; and ${ }^{\mathrm{b}}$ Department of Crystallography and \\ Structural Biology, Instituto de Química Física "Rocasolano," Spanish National Research Council, 28006 Madrid, Spain
}

Edited by Daniel Kahne, Harvard University, Cambridge, MA, and approved February 5, 2020 (received for review October 11, 2019)

In oval-shaped Streptococcus pneumoniae, septal and longitudinal peptidoglycan syntheses are performed by independent functional complexes: the divisome and the elongasome. Penicillin-binding proteins (PBPs) were long considered the key peptidoglycan-synthesizing enzymes in these complexes. Among these were the bifunctional class A PBPs, which are both glycosyltransferases and transpeptidases, and monofunctional class B PBPs with only transpeptidase activity. Recently, however, it was established that the monofunctional class B PBPs work together with transmembrane glycosyltransferases (FtsW and RodA) from the shape, elongation, division, and sporulation (SEDS) family to make up the core peptidoglycan-synthesizing machineries within the pneumococcal divisome (FtsW/PBP2x) and elongasome (RodA/PBP2b). The function of class A PBPs is therefore now an open question. Here we utilize the peptidoglycan hydrolase CbpD that targets the septum of $S$. pneumoniae cells to show that class A PBPs have an autonomous role during pneumococcal cell wall synthesis. Using assays to specifically inhibit the function of PBP2x and FtsW, we demonstrate that CbpD attacks nascent peptidoglycan synthesized by the divisome. Notably, class A PBPs could process this nascent peptidoglycan from a CbpD-sensitive to a CbpD-resistant form. The class A PBP-mediated processing was independent of divisome and elongasome activities. Class A PBPs thus constitute an autonomous functional entity which processes recently formed peptidoglycan synthesized by FtsW/PBP2x. Our results support a model in which mature pneumococcal peptidoglycan is synthesized by three functional entities, the divisome, the elongasome, and bifunctional PBPs. The latter modify existing peptidoglycan but are probably not involved in primary peptidoglycan synthesis.

class A PBPs | CbpD | peptidoglycan | Streptococcus pneumoniae

T he peptidoglycan layer covering the pneumococcal cell provides shape and rigidity and is essential for growth and survival. It consists of linear chains of two alternating amino sugars, $N$-acetylglucosamine (GlcNAc) and $N$-acetylmuramic acid (MurNAc), interlinked by peptide bridges between MurNAcs on adjacent strands $(1,2)$. Peptidoglycan is synthesized from lipid II precursors on the outside of the cytoplasmic membrane by glycosyltransferases that polymerize the glycan chains and transpeptidases that interconnect the chains through peptide cross-links. Streptococcus pneumoniae produces five different penicillin-binding proteins (PBPs) with transpeptidase activity, namely, PBP1a, PBP1b, PBP2a, PBP2b, and PBP2x (3). The first three of these, designated class A PBPs, are bifunctional enzymes that catalyze transglycosylation as well as transpeptidation, while PBP2x and PBP2b are monofunctional transpeptidases (class B PBPs) (4). Monofunctional glycosyltransferases that have homology to the glycosyltransferase domains of class A PBPs are present in some bacterial species but are absent from $S$. pneumoniae. PBP2x is an essential constituent of the divisome, a multiprotein division machine that synthesizes the septal cross wall (3, 5-7). The other monofunctional transpeptidase, PBP2b, is a key component of another multiprotein complex, the elongasome, which is responsible for longitudinal peptidoglycan synthesis $(3,5-$ 8). Until recently, it was believed that only class A PBPs were able to polymerize glycan chains in $S$. pneumoniae. Consequently, the divisome as well as the elongasome would have to include at least one class A PBP in order to be functional. Recently, however, it was discovered that FtsW and RodA, two proteins belonging to the SEDS (shape, elongation, division, and sporulation) family, function as peptidoglycan polymerases that synthesize glycan strands from lipid II (9-11). FtsW and RodA were originally reported to be lipid II flippases, a function now assigned to MurJ (12). However, it is still not entirely clear whether these polytopic membrane proteins are monofunctional glycan polymerases or bifunctional flippases and polymerases $(13,14)$. Previous research has shown that FtsW and RodA are essential and work in conjunction with PBP2x and PBP2b, respectively $(9,11)$.

Peptidoglycan synthesis requires the concerted action of enzymes that carry out transglycosylation and transpeptidation reactions. Thus, in principle, peptidoglycan synthesis might be performed by monofunctional transglycosylases working together with monofunctional transpeptidases, by single bifunctional enzymes such as the class A PBPs, or by a combination of monofunctional and bifunctional enzymes. As mentioned above, class A PBPs have traditionally been considered to be essential components of bacterial divisomes and elongasomes. However, it has been known for a long time that $\mathrm{Ba}$ cillus subtilis is viable without class A PBPs (15). Thus, considering the recent discovery of the SEDS partners of PBP2x and $\mathrm{PBP} 2 \mathrm{~b}$, it is conceivable that the pneumococcal divisome and elongasome perform the primary synthesis of septal and peripheral peptidoglycan

\section{Significance}

Peptidoglycan, the main structural component of the bacterial cell wall, is made of glycan strands cross-linked by short peptides. It has long been assumed that class A penicillin-binding proteins (PBPs) are the only enzymes capable of synthesizing glycan strands from lipid II. Recently, however, it was discovered that two non-PBP proteins, FtsW and RodA, constitute the core peptidoglycan polymerizing enzymes of the divisome and elongasome, respectively. What, then, is the role of class A PBPs in the construction of the bacterial cell wall? In contrast to previous assumptions, our results strongly suggest that class $\mathrm{A}$ PBPs are not an intrinsic part of the divisome and elongasome but have important autonomous roles in construction of the fully mature bacterial cell wall.

Author contributions: D.S., M.K., and L.S.H. designed research; D.S., K.W.P., S.O., G.A.S., K.H.B., M.K., and M.V.H. performed research; D.S., K.W.P., S.O., G.A.S., K.H.B., M.K., M.V.H., M.A., J.A.H., and L.S.H. analyzed data; and D.S., M.K., J.A.H., and L.S.H. wrote the paper.

The authors declare no competing interest.

This article is a PNAS Direct Submission.

This open access article is distributed under Creative Commons Attribution-NonCommercialNoDerivatives License 4.0 (CC BY-NC-ND).

${ }^{1}$ D.S. and K.W.P. contributed equally to this work

${ }^{2}$ To whom correspondence may be addressed. Email: sigve.havarstein@nmbu.no.

This article contains supporting information online at https://www.pnas.org/lookup/suppl/ doi:10.1073/pnas.1917820117/-/DCSupplemental.

First published March 2, 2020. 
without the involvement of class A PBPs. If so, the function of class A PBPs is an open question, and their role in peptidoglycan synthesis must be reexamined. Here we have addressed this question by exploiting the unique properties of the peptidoglycan hydrolase CbpD (choline-binding protein $\mathrm{D}$ ).

CbpD is composed of three domains: an N-terminal cysteine, histidine-dependent amidohydrolase/peptidase (CHAP) domain, one or two Src homology 3b (SH3b) domains, and a C-terminal choline-binding domain (Cbd) consisting of four choline-binding repeats (16). CHAP domains are present in many peptidoglycan hydrolases and function as either $N$-acetylmuramoyl-L-alanine amidases or endopeptidases $(17,18)$. Hence, the CHAP domain of $\mathrm{CbpD}$ cleaves somewhere within the peptide bridges of streptococcal peptidoglycan. However, the exact bond cleaved has not been identified. The SH3b domain is essential for the function of $\mathrm{CbpD}$, and experimental evidence indicates that it binds to the peptidoglycan portion of the cell wall (16). The choline-binding repeats of the Cbd domain anchor CbpD to cell wall teichoic acid and possibly also lipoteichoic acid through noncovalent interactions with the choline residues decorating these polymers (19). Similar to the CHAP and SH3b domains, the Cbd domain is essential for the biological function of CbpD (16).

Even though $\mathrm{CbpD}$ appears to be a key component of the pneumococcal gene transfer machinery, it is still poorly characterized. In the present study, we were able to purify the CbpD protein from Streptococcus mitis B6 (CbpD-B6) and show that it specifically cleaves nascent peptidoglycan formed by the pneumococcal PBP2x/FtsW machinery. We utilized this unique specificity of $\mathrm{CbpD}$ to study the functional relationships between different peptidoglycan-synthesizing enzymes in S. pneumoniae. Our results strongly indicate that class A PBPs are not part of the core machineries of the divisome and elongasome but have an important autonomous role in the construction of the fully matured peptidoglycan layer.

\section{Results}

CbpD-B6 Attacks the Septal Area of the Pneumococcal Cell Wall. It has previously proved very difficult to express and purify the pneumococcal peptidoglycan hydrolase $\mathrm{CbpD}$ from $S$. pneumoniae strain R6 (CbpD-R6). In order to further study the properties of this enzyme, we therefore searched for homologous CbpD variants in other streptococcal species. The $\mathrm{CbpD}$ allele from $S$. mitis B6 (CbpD-B6) is highly homologous to CbpD-R6. Their CHAP and Cbd domains are $96 \%$ and $95 \%$ identical, respectively. The major difference between them is that CbpD-R6 contains an extra SH3b domain (SI Appendix, Fig. S1). We were able to successfully purify CbpD-B6 using diethylaminoethyl (DEAE) cellulose affinity chromatography (20) and size exclusion chromatography (SI Appendix, Fig. S2). The R6 strain is highly sensitive to CbpD-B6, and a concentration of $0.3 \mu \mathrm{g} \mathrm{mL}^{-1}$ lyses $50 \%$ of the cells in an R6 culture at an optical density at $550 \mathrm{~nm}\left(\mathrm{OD}_{550}\right)$ of 0.2 (see the titration experiment in SI Appendix, Fig. S3). To rule out the possibility that lysins from the Escherichia coli expression host contaminated the CbpD-B6 protein preparation, a control experiment was performed in which choline ( $2 \%$ final concentration) was added together with the CbpD-B6 preparation to the pneumococcal culture. Exogenously added choline binds to the Cbd domain of CbpD-B6 and inhibits its function by blocking its binding to the choline residues decorating pneumococcal teichoic acids (20). No lysis was observed in the presence of $2 \%$ choline (SI Appendix, Fig. S4). As no choline-binding lysins are produced by E. coli, this shows that the observed muralytic activity is caused by CbpD-B6. The purified CbpD-B6 protein preparation was therefore used for further studies.

Pneumococci exposed to purified recombinant CbpD-B6 were examined by scanning electron microscopy (SEM) for visualization of changes in their ultrastructure. The SEM microscopy analysis clearly showed that CbpD-B6 attacks only the septal region of the peptidoglycan sacculus, resulting in cells that are split in half along their equators (Fig. 1). Interestingly, the rims of both hemispheres in the split cells are thicker than the rest of the peptidoglycan layer. This suggests that $\mathrm{CbpD}-\mathrm{B} 6$ cleaves the cells along the middle of the equatorial ring, also called the piecrust.

\section{CbpD-B6 Specifically Cleaves Nascent Peptidoglycan Formed by PBP2x} and FtsW. Since CbpD-B6 attacks the septal region of the cell, we speculated that the enzyme targets the peptidoglycan formed by PBP2x and FtsW. If so, specific inhibition of the divisome activity might render pneumococci less sensitive or insensitive to CbpD-B6. In a recent profiling of the $\beta$-lactam selectivity of pneumococcal PBPs, Kocaoglu et al. (21) showed that PBP2x is more sensitive than PBP1a, PBP1b, PBP2a, and PBP2b to several different $\beta$-lactams. Hence, by using the appropriate $\beta$-lactam at the right concentration it should be possible to inhibit the transpeptidase activity of PBP2x without significantly affecting the function of the other PBPs. To test this hypothesis, we grew pneumococcal cultures in 96-well plates in a microplate reader at $37{ }^{\circ} \mathrm{C}$. When reaching $\mathrm{OD}_{550} \sim 0.2$, each culture was treated with a different concentration of oxacillin. The oxacillin concentrations used ranged from 0 to $100 \mu \mathrm{g} \mathrm{mL}{ }^{-1}$, i.e., from sub- to supra-minimum inhibitory concentrations (MICs). Ten minutes after being exposed to oxacillin, each culture received $5 \mu \mathrm{g} \mathrm{mL}^{-1}$ of purified CbpD-B6. Comparison of the lytic responses of the cultures showed that the extent of lysis gradually decreased with increasing oxacillin concentrations until the cells became resistant to CbpD-B6 at concentrations between 0.19 and $6.1 \mu \mathrm{g} \mathrm{mL}^{-1}$ (Fig. $2 A$ ). The lowest antibiotic concentration that gave full protection against CbpD-B6 $\left(0.19 \mu \mathrm{g} \mathrm{mL}^{-1}\right)$ corresponds roughly to the MIC value of oxacillin against the R6 strain (SI Appendix, Fig. S5A). However, to our great surprise, the pneumococci started to lyse again when the concentration of oxacillin was increased further, i.e., above $6.1 \mu \mathrm{g} \mathrm{mL} \mathrm{mL}^{-1}$. At the highest oxacillin concentrations used $(50$ and $\left.100 \mu \mathrm{g} \mathrm{mL}^{-1}\right)$, the pneumococci became as sensitive as untreated control cells (Fig. $2 A$ ). In sum, the results show that as the oxacillin concentration is gradually increased, the lytic response to CbpD-B6 shifts from decreasing sensitivity (S1 phase) to resistance ( $\mathrm{R}$ phase) and then back to increasing sensitivity (S2 phase).

In line with the observations above (Fig. 1), GFP-CbpD has previously been shown to mainly bind the septal region of pneumococcal cells, and the binding specificity is determined by the C-terminal choline-binding domain (16). To test whether CbpD resistance during the $\mathrm{R}$ phase could be explained by altered binding of $\mathrm{CbpD}$ after exposure to oxacillin, we analyzed the binding patterns of sfGFP-CbpD-B6 as previously described (16). The fusion protein was expressed and purified essentially as CbpD-B6 and exposed to RH425 control cells as well as RH425 cells treated with $0.8 \mu \mathrm{g} \mathrm{mL}^{-1}$ oxacillin for $10 \mathrm{~min}$ (resulting in $\mathrm{R}$ phase cells, Fig. $2 A$ ). sfGFP-CbpD-B6 retained the localization to the septal region after oxacillin treatment for cells in all division stages (Fig. $3 A$ ), although the fraction of cells without septal sfGFP-CbpD-B6 was slightly higher than in the control cells $(6.7 \%$ in control cells and $11.8 \%$ after oxacillin treatment, Fig. $3 B$ ). This shows that the $\mathrm{R}$ phase cannot be explained by alterations in the binding pattern of sfGFP-CbpD-B6.

Beta-lactam-resistant pneumococci have acquired so-called low-affinity PBPs, modified PBPs that have much lower affinity for $\beta$-lactams than the corresponding PBPs of sensitive strains. To verify that the $\mathrm{R}$ phase is due to inhibition of PBP2x by oxacillin, the experiment described above was repeated with an R6 mutant strain (KHB321) expressing a low-affinity version of PBP2x (SI Appendix, Fig. S5B). The KHB321 mutant was constructed by replacing the extracytoplasmic part of R6-pbp $2 x$ with the corresponding part of the low-affinity $p b p 2 x$ gene from 

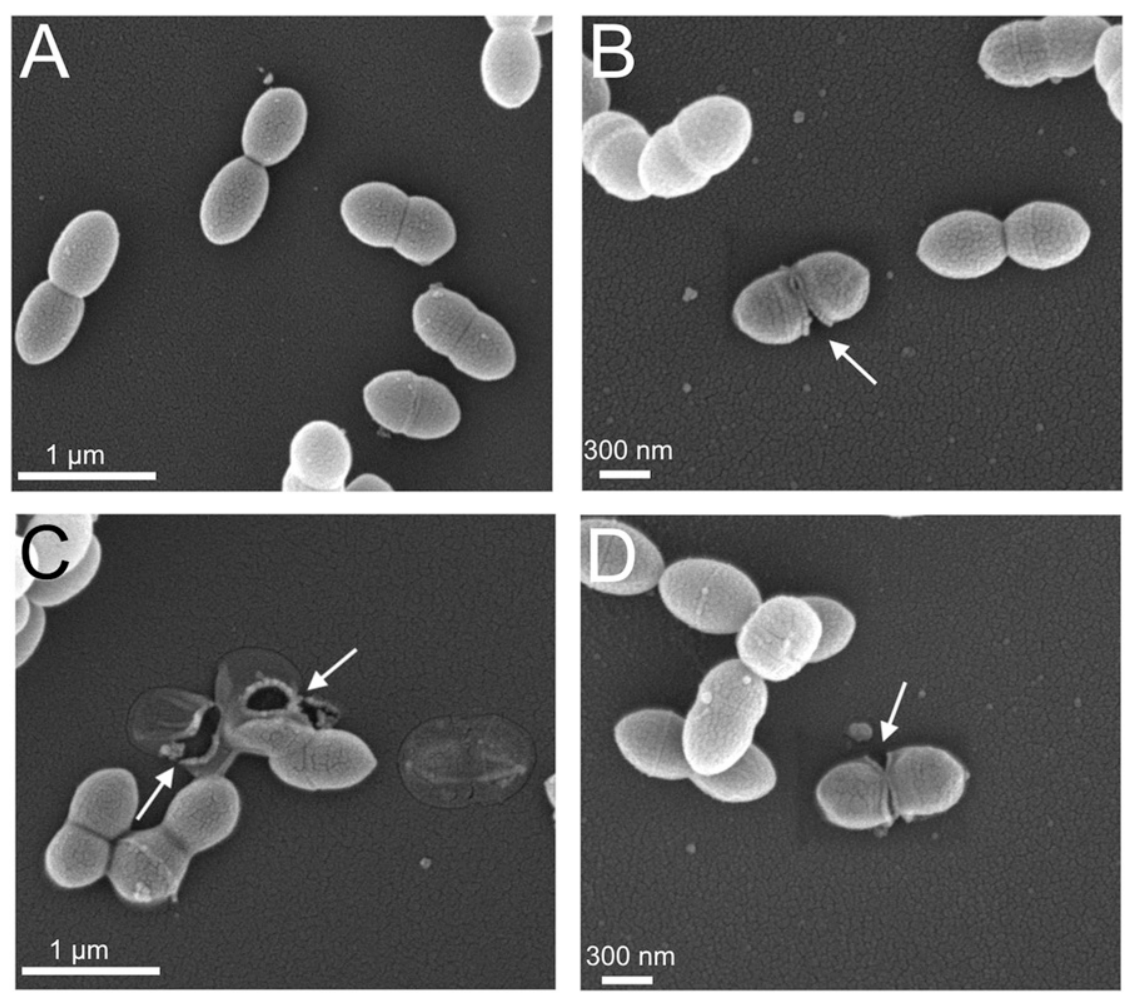

Fig. 1. CbpD-B6 specifically attacks the septal region. Scanning electron micrographs of untreated pneumococci $(A)$ and pneumococci subjected to $0.5 \mu \mathrm{g} \mathrm{mL}^{-1}$ CbpD-B6 for $60 \mathrm{~s}$ before they were fixed and prepared for electron microscopy $(B-D)$. Arrows indicate areas in the cell wall attacked by the muralytic enzyme.

S. mitis strain B6 (SI Appendix, Fig. S6). The B6 strain is a highly penicillin resistant clinical isolate that produces low-affinity versions of PBP2x, PBP2b, and PBP1a (22). When the oxacillin titration experiment was carried out with the KHB321 strain, no
$\mathrm{R}$ phase was obtained within the concentration range used $(0$ to $100 \mu \mathrm{g} \mathrm{mL} \mathrm{L}^{-1}$ oxacillin) (Fig. $2 B$ ). This result clearly shows that inhibition of the transpeptidase activity of PBP2x by oxacillin causes the $\mathrm{R}$ phase.
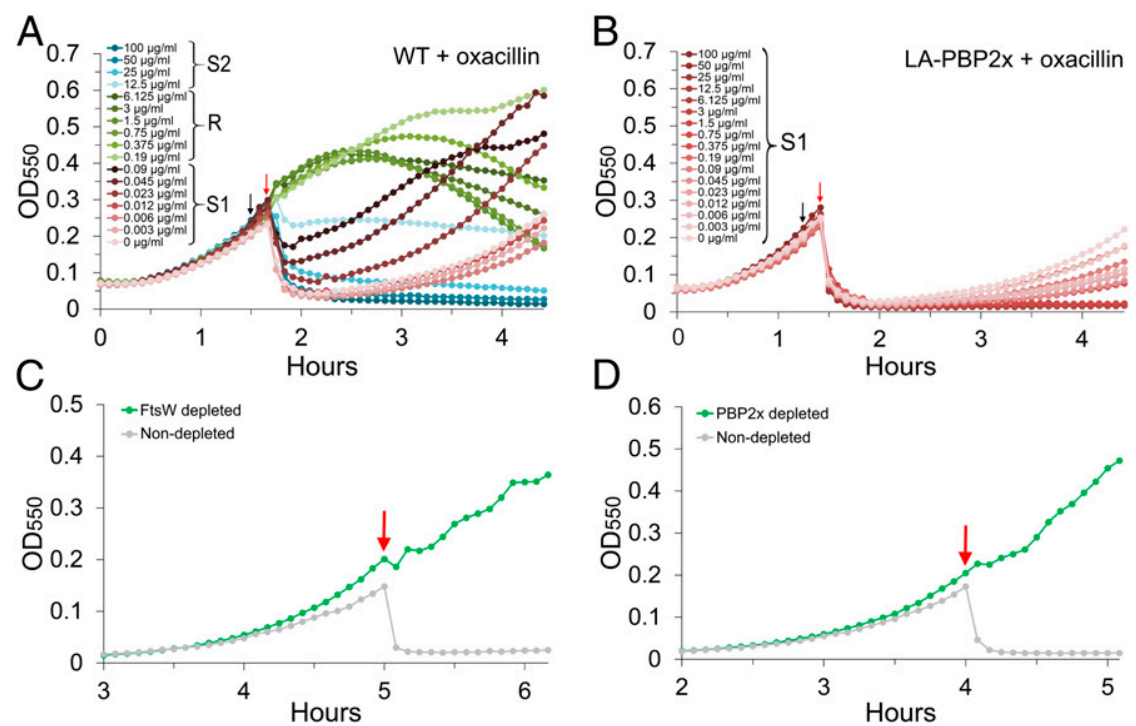

Fig. 2. Inhibition of the core peptidoglycan-synthesizing machinery of the divisome (PBP2x/FtsW) produces CbpD-B6-resistant peptidoglycan. (A) Increasing concentrations of oxacillin were added to exponentially growing wild-type (WT) cells (RH425) at $\mathrm{OD}_{550} \sim 0.25$ (black arrow). After 10 min, CbpD-B6 was added (red arrow) to a final concentration of $5 \mu \mathrm{g} \mathrm{mL}^{-1}$. The cells were susceptible to CbpD-B6 at concentrations ranging from 0 to $0.09 \mu \mathrm{g} \mathrm{mL} \mathrm{L}^{-1}$ oxacillin (S1 phase, red curves), resistant from 0.19 to $6.125 \mu \mathrm{g} \mathrm{mL}^{-1}$ (R phase, green curves), and susceptible from 12.5 to $100 \mu \mathrm{g} \mathrm{mL}^{-1}$ (S2 phase, blue curves). (B) Pneumococci expressing a PBP2x homolog (LA-PBP2x, strain KHB321) with low affinity for $\beta$-lactam antibiotics did not give rise to CbpD resistance when subjected to increasing concentrations of oxacillin. ( $C$ and $D$ ) Strong depletion (green curves) of FtsW (strain css12) and PBP2x (strain SPH163) results in cells resistant to CbpD-B6 (red arrows indicate addition of $5 \mu \mathrm{g} \mathrm{mL} \mathrm{L}^{-1}$ of CbpD-B6). 


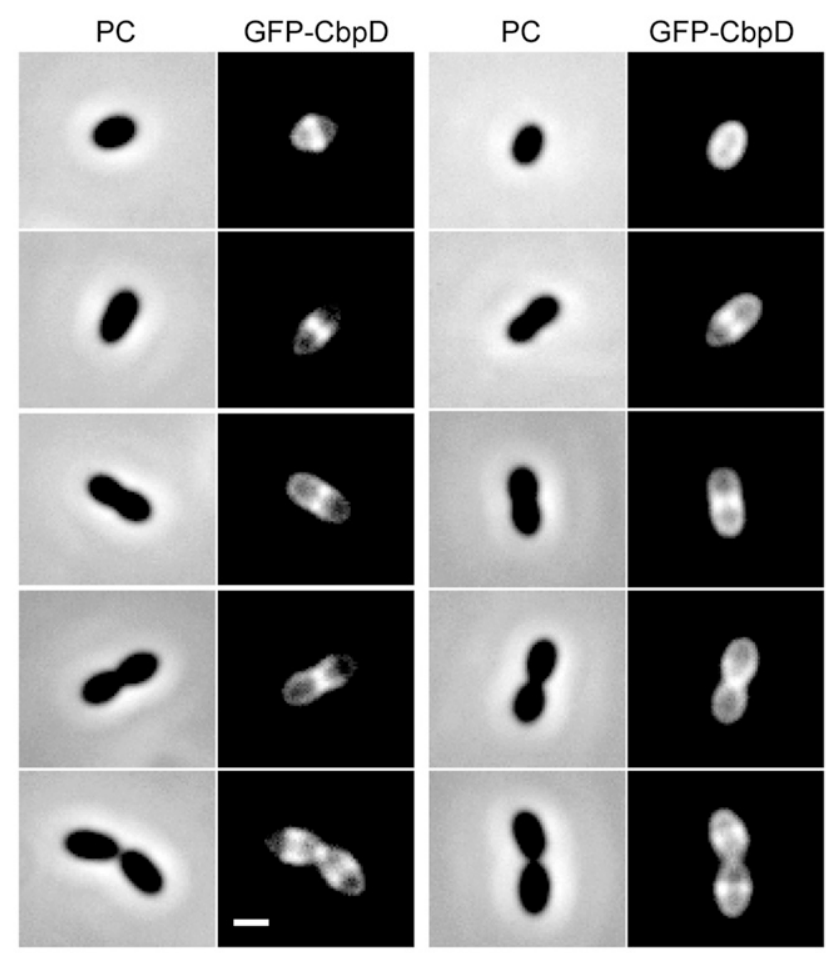

B

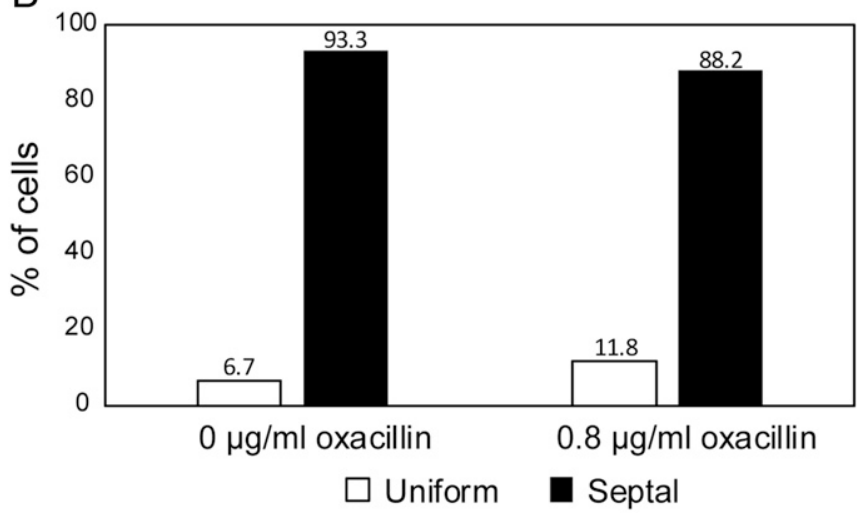

Fig. 3. Binding of sfGFP-CbpD-B6 to oxacillin-treated S. pneumoniae RH425 cells. (A) Binding of sfGFP-CbpD-B6 to fixed S. pneumoniae cells in five stages of division. Phase contrast (PC) and GFP images of nontreated control cells (0 $\mu \mathrm{g} \mathrm{mL}^{-1}$ oxacillin, S1 phase cells) and cells treated with $0.8 \mu \mathrm{g} \mathrm{mL}^{-1}$ oxacillin for $10 \mathrm{~min}$ (R phase cells) are included. (B) Proportion of cells with sfGFPCbpD-B6 enriched in the septal region for both groups of cells. The numbers of oxacillin-treated and nontreated cells analyzed were 170 and 180 respectively. The scale bar is $1 \mu \mathrm{m}$.

Moreover, the results above show that CbpD-B6 specifically attacks the peptidoglycan formed by PBP2x/FtsW in the divisome. To further substantiate this conclusion, we investigated whether loss of FtsW activity would give rise to resistance against CbpD-B6. Since FtsW is essential and no specific inhibitor is known, we decided to deplete the expression of this peptidoglycan polymerase using the ComRS system (see Western blot in SI Appendix, Fig. S7) as described before $(8,23)$. Supporting our conclusion, the results showed that strongly depleted cells became fully resistant to CbpD-B6 (Fig. 2C). As expected, depletion of PBP2x gave the same result (Fig. 2D). The morphology of pneumococcal cells strongly depleted of PBP2x (8) or FtsW (SI Appendix, Fig. S7) is the same; both become elongated and somewhat enlarged.
The S2 Phase Results from Inhibition of the PBPs Processing PBP2x/ FtsW-Synthesized Peptidoglycan. During the S1 phase the oxacillin concentration increases gradually, resulting in progressively stronger inhibition of PBP2x. This causes a gradual reduction in the number of nascent peptide bridges formed by PBP2x and, eventually, complete inhibition of its transpeptidase activity in the $\mathrm{R}$ phase. While this line of reasoning provides an explanation for the S1 and R phases, it does not explain the S2 phase. How can a further increase in oxacillin concentration lead to increased cell lysis when PBP2x is completely inhibited? We observed that the $\mathrm{R}$ phase disappears if oxacillin $\left(0.8 \mu \mathrm{g} \mathrm{mL} \mathrm{m}^{-1}\right)$ and CbpD-B6 are added simultaneously to pneumococcal cultures. After being exposed to oxacillin it takes about $3.5 \mathrm{~min}$ before $95 \%$ of the cells develop full resistance against CbpD-B6 (Fig. 4). This shows that the peptidoglycan initially formed by the PBP2x/FtsW machinery must undergo some kind of processing before it becomes resistant to $\mathrm{CbpD}-\mathrm{B} 6$, an operation that takes several minutes. This finding suggested a plausible explanation for the S2 phase. Although PBP2x is more sensitive than the other pneumococcal PBPs to oxacillin, a further increase in oxacillin concentration will eventually affect the transpeptidase activity of the less sensitive PBPs. Presumably, the activity of one or more of these PBPs is required to modify $\mathrm{PBP} 2 \mathrm{x} / \mathrm{FtsW}$-synthesized peptidoglycan into a CbpD-B6-resistant form. Consequently, the cells will not become resistant if their activity is blocked. The reason for this is that newly synthesized CbpD-B6-sensitive peptidoglycan will still be present if the activities of PBP2x and the PBP(s) required for processing this peptidoglycan are blocked simultaneously. In sum, our results indicate that the S2 phase results from inhibition of the $\mathrm{PBP}(\mathrm{s})$ required for processing $\mathrm{PBP} 2 \mathrm{x}$ FtsW-synthesized peptidoglycan into a CbpD-B6-resistant form.

Peptidoglycan Synthesized by the FtsW/PBP2x Machinery Is Further Processed by Class A PBPs. To determine whether class A PBPs are required to produce CbpD-B6-resistant peptidoglycan, the oxacillin titration experiment described above was performed in the presence of $10 \mu \mathrm{g} \mathrm{mL}^{-1}$ of the antibiotic moenomycin. Moenomycin inhibits bacterial growth by blocking the transglycosylase activity of class $\mathrm{A}$

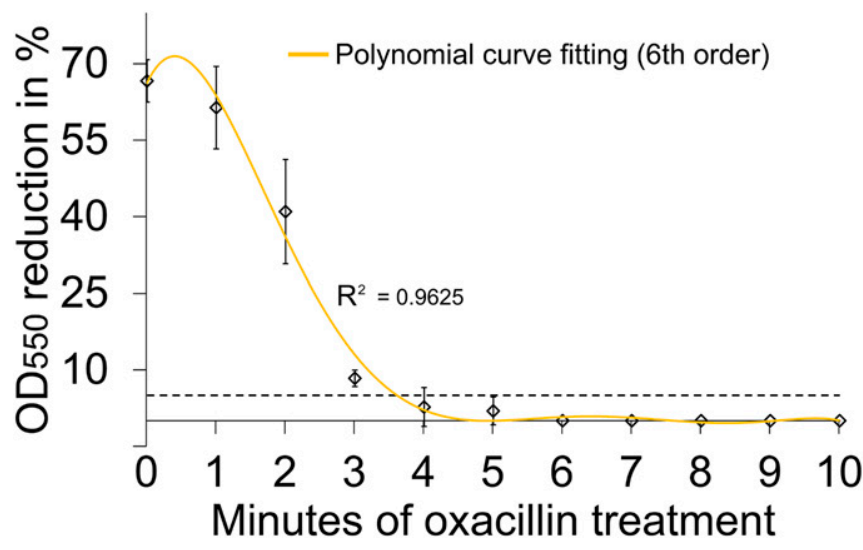

Fig. 4. Kinetics of $\mathrm{CbpD}$ resistance development in pneumococcal cells where PBP2x/FtsW-mediated peptidoglycan synthesis has been blocked by the addition of $0.8 \mu \mathrm{g} \mathrm{mL}^{-1}$ oxacillin. Oxacillin was added simultaneously to 11 parallel cultures of wild-type cells at $O_{550} \sim 0.25$. To check for sensitivity to $\mathrm{CbpD-B6}, 1 \mu \mathrm{g} \mathrm{mL} \mathrm{L}^{-1}$ of the hydrolase was added to a different culture every minute for 0 to $10 \mathrm{~min}$. The results are presented as percent reduction in $\mathrm{OD}_{550}$ caused by cell lysis. After about $3.5 \mathrm{~min} 95 \%$ of the cells were resistant to CbpD-B6 (dashed line), demonstrating that pneumococcal cells need time to transform newly synthesized septal peptidoglycan into a CbpDB6-resistant form. Mean estimates $(n=3)$ together with their SDs are shown. The curve was fitted using a sixth-order polynomial equation (see Materials and Methods). 
PBPs but does not affect FtsW and RodA (9). Our results showed that in the presence of moenomycin the S1-R-S2 pattern disappeared, and the pneumococci were sensitive to CbpD-B6 at all oxacillin concentrations used (0 to $100 \mu \mathrm{g} \mathrm{mL}^{-1}$ oxacillin) (Fig. $5 \mathrm{~A}$ and $F$ ). The disappearance of the $\mathrm{R}$ phase did not result from autolysis induced by cotreatment of the cells with moenomycin and oxacillin (SI Appendix, Fig. S8) but was caused by a change in the sensitivity to CbpD-B6. This demonstrates that without functional class A PBPs, nascent peptidoglycan is not converted to the CbpDB6-resistant form.

As three different class A PBPs are produced by $S$. pneumoniae (PBP1a, PBP1b, and PBP2a) we wondered whether the
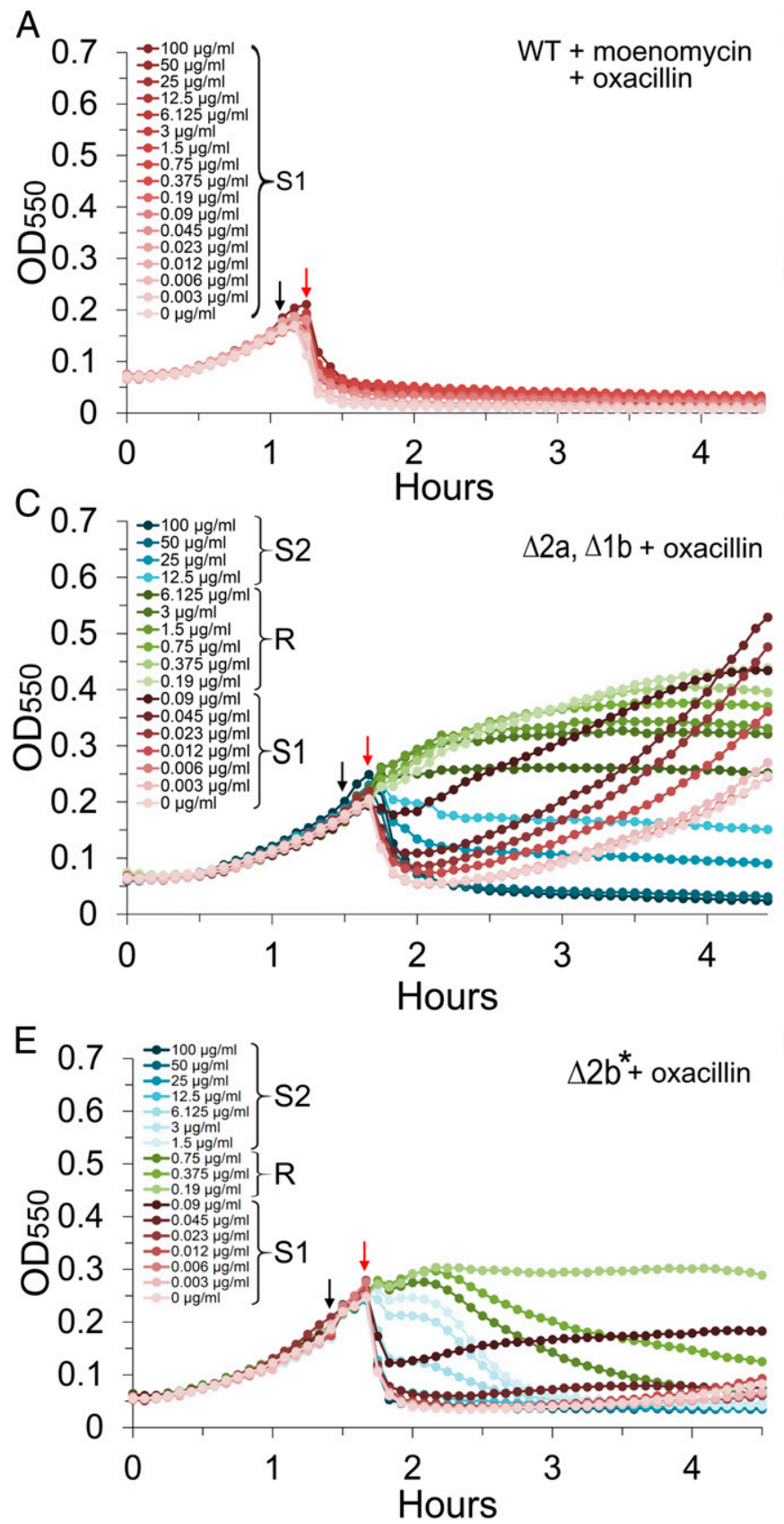

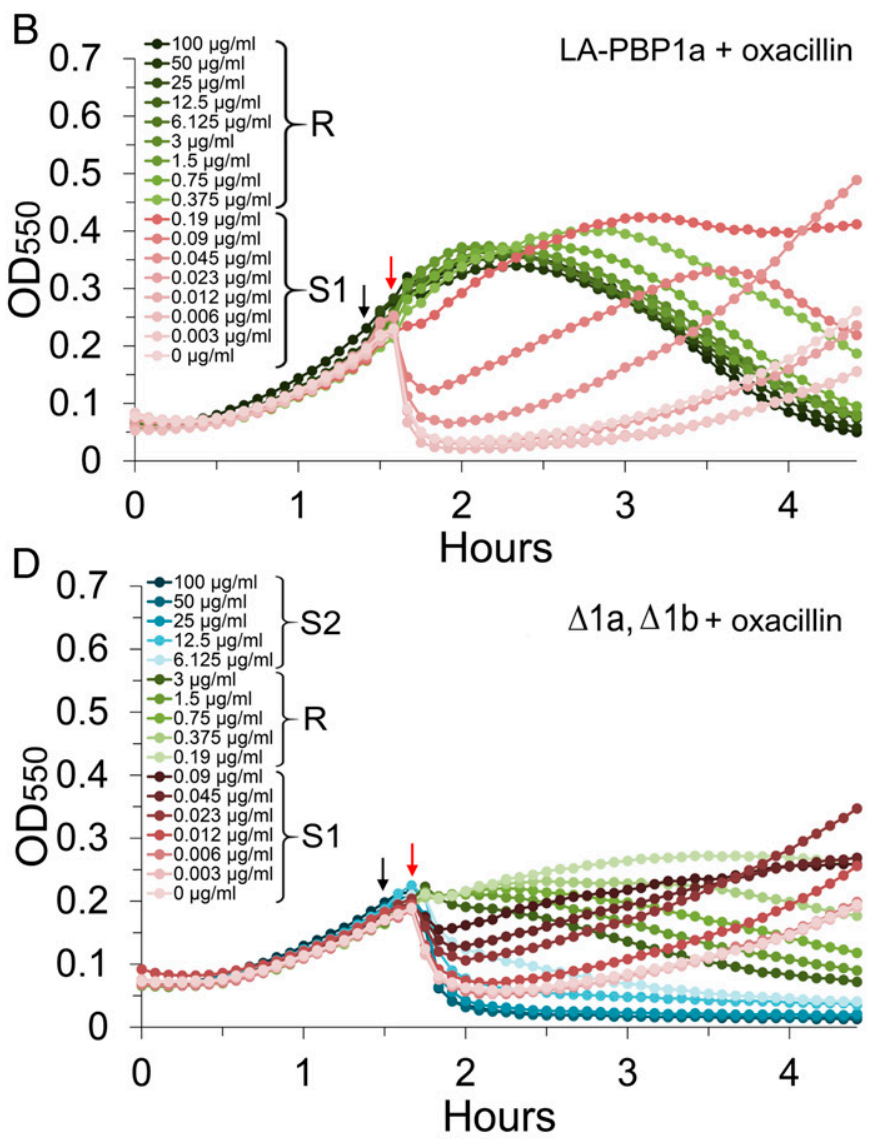

$\mathrm{F}$

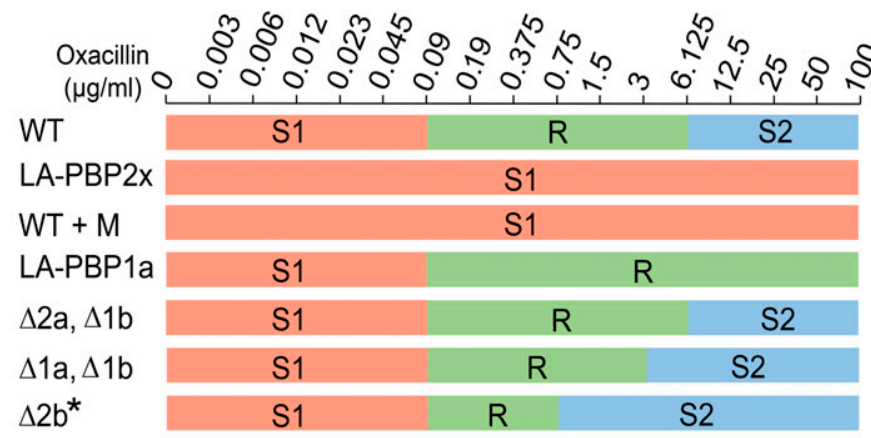

Fig. 5. CbpD sensitivity assays $(A-E)$ demonstrating that class A PBPs are essential for converting PBP2x/FtsW-synthesized peptidoglycan into a CbpD-B6 resistant form. Resistance to CbpD-B6 was tested for different pneumococcal mutants after treatment with different concentrations of oxacillin alone or in combination with moenomycin. Black arrows indicate the addition of antibiotics, while red arrows indicate the addition of CbpD-B6 $\left(5 \mu \mathrm{g} \mathrm{mL} \mathrm{L}^{-1}\right) 10 \mathrm{~min}$ later. (A) RH425 cultures treated with moenomycin $\left(10 \mu \mathrm{g} \mathrm{mL}^{-1}\right)$ in combination with the indicated concentrations of oxacillin before being subjected to CbpD-B6. (B) Cultures of a mutant strain expressing a low-affinity PBP1a (LA-PBP1a, strain KHB332). Individual cultures are treated with one of the indicated concentrations of oxacillin for 10 min before being subjected to CbpD-B6. (C) Same setup as in $B$, except that strain KHB225 ( $\Delta p b p 2 a / \Delta p b p 1 b)$ was used. (D) Same setup as in $B$, except that strain KHB224 ( $\Delta p b p 1 a / \Delta p b p 1 b)$ was used. (E) Same setup as in $B$, except that strain ds789 $\left(\Delta p b p 2 b, \Delta / y t A, m r e C^{\Delta a a 182-272}\right)$ was used and CbpD-B6 was added 15 min subsequent to oxacillin. $(F)$ Schematic summary of the sensitivity of different strains to CbpD-B6 based on the results presented in Figs. $2 A$ and $B$ and $5 A-E$. Three different phases were observed, namely, sensitivity phase 1 (S1), the resistant phase (R), and sensitivity phase 2 (S2). The oxacillin concentrations that gave rise to the different phases are indicated above the plot. $\Delta 2 b^{*}$ indicates that the genotype of strain ds 789 ( $\Delta p b p 2 b$, $\left.\Delta l y t A, m r e C^{\Delta a a 182-272}\right)$ is more complex than denoted in $E$ and $F$. All experiments were performed three times or more, with highly similar results. 
concerted action of all three is needed for the maturation process. To answer this question the oxacillin titration experiment was performed with a mutant strain expressing a low-affinity PBP1a protein from $S$. mitis B6. Using the same concentration range as before $(0$ to $100 \mu \mathrm{g} \mathrm{mL}^{-1}$ oxacillin), we only observed the $\mathrm{S} 1$ and $\mathrm{R}$ phases in this experiment. The S2 phase had disappeared and was replaced with an extended $\mathrm{R}$ phase (Fig. $5 B$ and $F$ ). This result shows that the activity of PBP1a alone is sufficient to transform PBP2x/FtsWsynthesized peptidoglycan into the CbpD-B6-resistant form.

The class A PBPs of $S$. pneumoniae strain R6 can be deleted one at a time and are therefore individually nonessential. PBP1a/ PBP1b and PBP2a/PBP1b double mutants can also be constructed, whereas PBP1a/PBP2a double mutants are nonviable $(6,7)$. The fact that pneumococcal cells need either PBP1a or PBP2a to survive indicates that these PBPs can, at least to a certain extent, substitute for each other. If the observed conversion of $\mathrm{PBP} 2 \mathrm{x} /$ FtsW-synthesized peptidoglycan into a CbpD-B6-resistant form represents an important element in the construction of a mature pneumococcal cell wall, it would be expected that this processing step can be carried out also by PBP2a. To address this question, we performed the oxacillin titration experiment with a $\Delta p b p 2 a$ / $\Delta p b p 1 b$ strain and a $\Delta p b p 1 a / \Delta p b p 1 b$ strain. In both cases we observed the typical $\mathrm{S} 1, \mathrm{R}$, and $\mathrm{S} 2$ phases (Fig. $5 C, D$, and $F$ ), demonstrating that PBP2a can substitute for PBP1a in the peptidoglycan maturation process.

Finally, to determine whether inhibition of class A PBPs has any effect on pneumococcal morphology, cells were treated with moenomycin for $2 \mathrm{~h}$ before they were fixed and prepared for transmission electron microscopy (TEM). The amount of moenomycin used $\left(0.4 \mu \mathrm{g} \mathrm{mL}{ }^{-1}\right.$, corresponding to $\left.0.5 \times \mathrm{MIC}\right)$ partially inhibits peptidoglycan polymerization by class A PBPs. The TEM micrographs revealed that moenomycin-treated cells had considerably thicker septal cross walls than untreated cells (Fig. $6)$. In addition, their cell walls were much less electron dense than wild-type ones, strongly indicating that they have little or no wall teichoic acid (24) or a more open peptidoglycan mesh structure.
PBP2b and the Elongasome. Having established that class A PBPs are essential for converting FtsW/PBP2x-synthesized peptidoglycan into a CbpD-B6 resistant form, we wanted to determine whether the process also requires an active elongasome. Unfortunately, we are not aware of any $\beta$-lactam or other drug to which PBP2b is more sensitive than the other pneumococcal PBPs. Consequently, we were not able to specifically inhibit the transpeptidase activity of $\mathrm{PBP} 2 \mathrm{~b}$ without running the risk of inhibiting the activity of the other PBPs as well. Instead, we carried out the oxacillin titration experiment with a $\Delta p b p 2 b$, $\Delta l y t A, \mathrm{MreC}^{\Delta \mathrm{aa} 182-272}$ mutant strain (strain ds789), which lacks a functional elongasome (25). PBP2b is essential in a wild-type background but can be deleted in a strain expressing a truncated version of the elongasome protein MreC (25). Moreover, since pneumococci depleted in PBP2b become hypersensitive to LytA (8), we deleted the $l y t A$ gene to avoid autolysis. Deletion of lyt $A$ does not affect the S1-R-S2 pattern observed when wild-type pneumococci are subjected to increasing concentrations of oxacillin (SI Appendix, Fig. S9). When performing this experiment, we observed the usual S1-R-S2 pattern (Fig. $5 E$ and $F$ ), but complete resistance was not reached when CbpD-B6 was added $10 \mathrm{~min}$ subsequent to oxacillin. However, after $15 \mathrm{~min}$ close to full resistance was obtained in cultures treated with 0.19 to $0.75 \mu \mathrm{g} \mathrm{mL}^{-1}$ oxacillin. This experiment shows that class A PBPs are able to process $\mathrm{PBP} 2 \mathrm{x} / \mathrm{FtsW}$-synthesized peptidoglycan in the absence of a functional elongasome.

\section{Discussion}

Recently, it became clear that FtsW/PBP2x and RodA/PBP2b constitute cognate pairs of interacting proteins that make up the core peptidoglycan-synthesizing machineries within the pneumococcal divisome and elongasome, respectively (9-11). Both couples consist of a monofunctional transglycosylase working together with a monofunctional transpeptidase. This discovery has important implications for our understanding of pneumococcal cell wall synthesis and the role played by class A PBPs in this process. Before it was discovered that the SEDS proteins FtsW and RodA have glycosyltransferase activity, class A PBPs
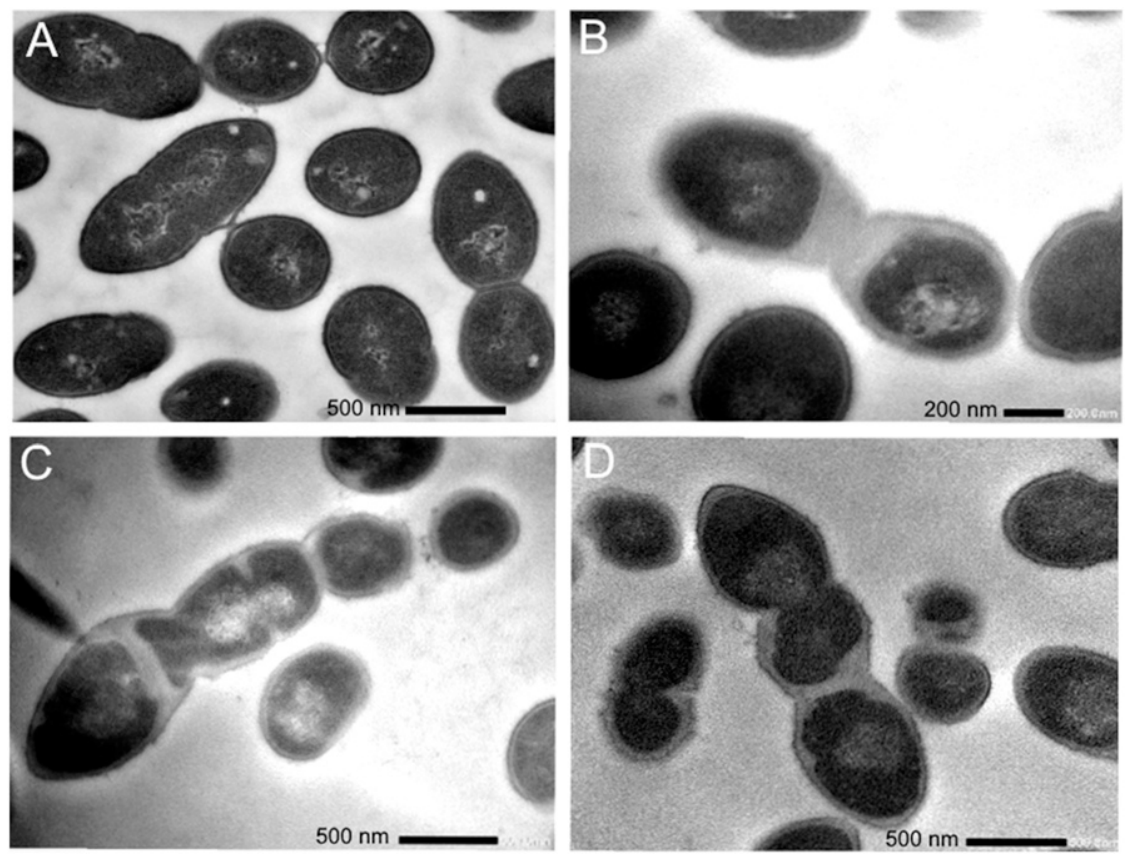

Fig. 6. TEM micrographs of $S$. pneumoniae RH425 cells grown without $(A)$ or with moenomycin $\left(0.4 \mu \mathrm{g} \mathrm{mL} \mathrm{L}^{-1}\right)$ for $2 \mathrm{~h}(B-D)$. The moenomycin-treated cells display thickened cell walls with low electron density, especially in the division zones. The experiment was performed twice with the same result. 
were considered to be the only peptidoglycan polymerases present in pneumococci. Hence, they were regarded as key components of the divisome and elongasome and indispensable for septal as well as peripheral peptidoglycan synthesis. This way of thinking is no longer valid, and the function of class A PBPs has therefore become an open question.

Using CbpD-B6 as a tool, we show that class A PBPs act downstream of the FtsW/PBP2x machinery to produce alterations in the cell wall. Class A PBPs are able to function, i.e., to convert FtsW/ PBP2x-synthesized peptidoglycan into a CbpD-B6-resistant form, even when PBP2x is completely inhibited by oxacillin. Similarly, we show that class A PBPs are able to operate independently of PBP2b and the elongasome in a $\Delta p b p 2 b, \Delta l y t A, \mathrm{MreC}^{\Delta \mathrm{aa} 182-272}$ mutant. Since the conversion process takes about $3.5 \mathrm{~min}$ (Fig. 4), the activity of class A PBPs occurs subsequent to and separate in time from FtsW/PBP2x-mediated peptidoglycan synthesis. These results are in agreement with the observation that the FtsW/PBP2x machinery as well as class A PBPs localize to the division site in $S$. pneumoniae (26). They also fit well with data obtained by high-resolution 3DSIM microscopy showing that the positions of PBP2x and PBP1a are similar in predivisional stages, while PBP1a lags behind PBP2x during septal constriction (27). Together our findings provide three important insights: 1) Class A PBPs have a distinct and unique role in the construction of the pneumococcal cell wall, 2) there exists a class A-mediated mechanism that remodels nascent FtsW/PBP2xsynthesized peptidoglycan into a more mature CbpD-B6-resistant form, and 3) this maturation mechanism is essential.

It is well established that the divisome and elongasome constitute two separate peptidoglycan-synthesizing machineries (5). Their activities are precisely coordinated during the cell cycle, but experiments have shown that the divisome is able to operate in the absence of the elongasome and vice versa. Pneumococcal cultures treated with oxacillin $\left(0.1 \mu \mathrm{g} \mathrm{mL}^{-1}\right)$ at a concentration that inhibits PBP2x, but not class A PBPs and PBP2b, give rise to highly elongated cells with no septal cross walls (SI Appendix, Fig. S10 $B$ and $C$ ). This demonstrates that the elongasome is active even in the absence of a functional divisome. Similar findings were reported previously by others $(5,27-29)$. In the opposite case, several studies showed that pneumococci are able to grow and form septal cross walls when PBP $2 b$ is depleted or deleted $(8,25,30,31)$. Pneumococci that are strongly depleted in $\mathrm{PBP} 2 \mathrm{~b}$ form long chains of round cells that are compressed in the direction of the long axis (SI Appendix, Fig. S10 $D$ and $E$ ). In the present study, we have obtained evidence that class A PBPs operate independently of the divisome and elongasome and hence function autonomously. An important question is therefore whether PBP1a, PBP2a, and PBP1b operate alone or in multiprotein complexes similar to the divisome and elongasome. It was reported that PBP1a forms a complex with CozE, MreC, and MreD (32) and that it coimmunoprecipitates with the cell cycle protein GpsB (33). Interestingly, it was shown that aberrant PBP1a activity can be detected outside the midcell zone in pneumococci lacking MreC or CozE, supporting the model that PBP1a can function autonomously (32). PBP2a, on the other hand, interacts with and is regulated by MacP, a substrate of the global cell cycle regulator StkP (34). The interplay between the two PBPs and their respective partners appears to be specific, as interactions between CozE/PBP2a and MacP/PBP1a have not been detected $(32,34)$. Presumably, the specific partners of PBP1a and PBP2a are important for the precise spatiotemporal regulation of their activity. Together the data support a model in which PBP1a, PBP2a, and PBP1b are the key players in three separate and autonomous peptidoglycan-synthesizing machineries with partially overlapping functions.

The fact that class A PBP-mediated remodeling of nascent peptidoglycan is inhibited by oxacillin as well as moenomycin strongly indicates that both catalytic domains of these proteins are actively involved in the remodeling process. Hence, the remodeling mechanism most likely involves the synthesis of new glycan strands and the incorporation of these strands into existing peptidoglycan (Fig. 7). How could peptidoglycan synthesis by class A PBPs make the cell wall resistant to CbpD-B6? The muralytic enzyme consists of three different domains, a catalytic CHAP domain, an SH3b domain, and a choline-binding domain that anchors CbpD-B6 to teichoic acid. The SH3b domain probably acts as an auxiliary module that binds peptidoglycan and facilitates the function of the catalytic CHAP domain (16). Previous research showed that all three domains are required for the enzyme to be active (16). Hence, it would be sufficient to block the function of one of these domains to convert the cell wall into a CbpD-B6-resistant form. Inhibiting the activity of the CHAP domain would require that nascent peptide bridges cross-linked by $\mathrm{PBP} 2 \mathrm{x}$ be altered to become resistant to the enzyme. A structural change in these peptide

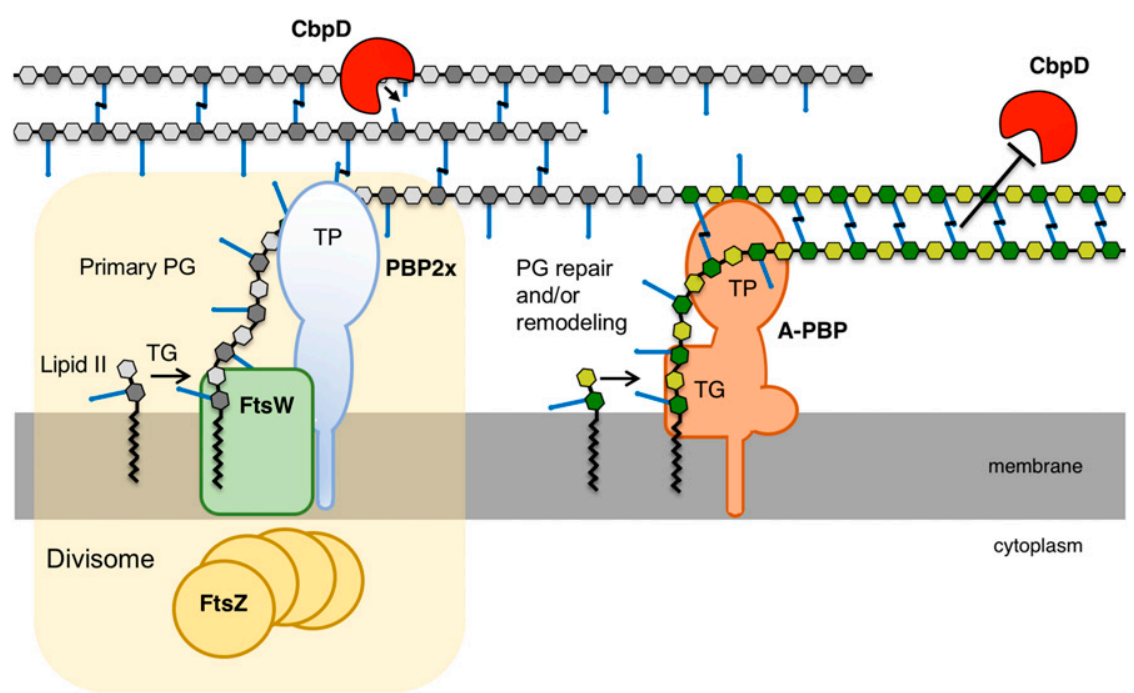

Fig. 7. Model illustrating the role of class A PBPs in the synthesis of pneumococcal peptidoglycan. The core peptidoglycan-synthesizing machinery, PBP2x and FtsW, of the divisome (yellow shading) produces the primary CbpD-sensitive peptidoglycan (shown in shades of gray), which is subsequently remodeled by class A PBPs into a CbpD-resistant form (shown in shades of green). 
bridges might also block the binding of the $\mathrm{SH} 3 \mathrm{~b}$ domain, as the $\mathrm{SH} 3 \mathrm{~b}$ domain of lysostaphin was reported to bind to the peptide part of the cell wall of Staphylococcus aureus (35). The peptide bridges in pneumococcal peptidoglycan consist of a mixture of branched and unbranched cross-links. The branches are introduced by the aminoacyl ligases MurM and MurN. MurM catalyzes the addition of L-Ala or L-Ser, whereas the addition of the second L-Ala is catalyzed by MurN (36). However, as a strain lacking murMN behaved exactly like the wild type when subjected to the oxacillin titration assay (SI Appendix, Fig. S11), alterations in branching are not important for CbpD-B6 resistance. Alternatively, we speculated that the $\mathrm{SH} 3 \mathrm{~b}$ domain recognizes the glycan part of pneumococcal peptidoglycan instead of the peptide part. Thus, the oxacillin titration assay was performed with $\triangle p g d A$ and $\Delta a d r$ mutant strains as well. The $p d g A$ gene encodes a peptidoglycan $N$-acetylglucosamine deacetylase, while the $a d r$ gene encodes a peptidoglycan $O$-acetyl transferase $(37,38)$. The $\Delta p g d A$ and $\Delta a d r$ strains displayed an S1-R-S2 pattern similar to the wild-type strain, demonstrating that neither $\mathrm{N}$-acetylation nor $\mathrm{O}$-acetylation significantly affects the ability of CbpD-B6 to cleave pneumococcal peptidoglycan during the S1 and S2 phases (SI Appendix, Fig. S12 $A$ and $B)$. Furthermore, it is possible that class A PBP-mediated remodeling of pneumococcal peptidoglycan affects the ability of CbpD-B6 to attach to teichoic acid via its C-terminal choline-binding domain, resulting in $\mathrm{CbpD}$ resistance. However, we could not detect any significant difference between cells treated with $0.8 \mu \mathrm{g} \mathrm{mL}^{-1}$ oxacillin ( $\mathrm{R}$ phase cells) and untreated cells with respect to sfGFP-CbpD-B6 binding patterns (Fig. 3).

Considering that $S$. pneumoniae must express either PBP1a or PBP2a to be viable, class A PBPs must serve an essential function. PBP1a appears to have the most prominent role among class A PBPs, as highly $\beta$-lactam resistant pneumococci always express low-affinity versions of PBP1a in addition to PBP2x and PBP2b. We clearly show that class A PBPs together with their associated auxiliary proteins somehow remodel the primary peptidoglycan synthesized by the PBP2x/FtsW machinery. As discussed above, this remodeling might involve chemical or structural modifications of the primary peptidoglycan that inhibit the function of the CHAP, SH3b, or Cbd domain of CbpD-B6. Alternatively, class A PBPs and their helper proteins might not synthesize peptidoglycan that is qualitatively different from the primary peptidoglycan synthesized by $\mathrm{PBP} 2 \mathrm{x} / \mathrm{FtsW}$, but rather might function as a repair machinery that mends imperfections that arise during construction and expansion of the cell wall (10). This idea is in accordance with the findings of a recently published study on E. coli. Vigouroux et al. (39) reported that PBP1b, the major class A PBP in this species, contributes to maintain cell wall integrity by actively repairing cell wall defects. It is conceivable that the peptidoglycan layer synthesized by $\mathrm{PBP} 2 \mathrm{x} / \mathrm{FtsW}$, i.e., the divisome, is not perfect. It might not be fully homogenous but might contain irregularities in the form of gaps and small holes. We speculate that CbpD-B6 uses these irregularities to penetrate into the peptidoglycan layer. Perhaps CbpD-B6 is not able to digest "tightly woven" peptidoglycan but depends on imperfections to get access to its substrate.

TEM micrographs of pneumococci treated with moenomycin showed that the electron density of their cross walls was strongly reduced (Fig. 6). This supports the idea that PBP2x/FtsWsynthesized peptidoglycan has less wall teichoic acid and/or a more open architecture. The pore size of peptidoglycan has been estimated to be around $2 \mathrm{~nm}$ (40). This represents a formidable physical barrier to the assembly of large proteins and cell wallspanning complexes that are larger than the pores. In the case of peptidoglycan-spanning machineries such as flagella and type III and IV secretion systems, the problem was solved by the recruitment of lytic transglycosylases or other muralytic enzymes that locally rearrange the cell wall (41). By analogy, it was assumed that muralytic enzymes create gaps in the peptidoglycan layer to allow the insertion or penetration of large proteins and pili $(42,43)$. However, if the peptidoglycan synthesized by PBP2x/FtsW inherently is more open, i.e., has more gaps and/or larger pores, it would facilitate the insertion of larger protein components, and local degradation of peptidoglycan might not be necessary. This idea fits with the fact that most bacterial proteins translocated across the cytoplasmic membrane are exported by the general secretory SecA-YEG pathway which is localized at midcell septa $(44,45)$.

We propose a model in which class A PBPs further process the peptidoglycan meshwork synthesized by PBP2x and FtsW to remove imperfections and/or make it denser (Fig. 7). A denser peptidoglycan can be obtained by adding peptidoglycan that is more heavily cross-linked or by introducing more wall teichoic acid. Thus, class A PBPs might together constitute a repairosome that repairs gaps and imperfections in the primary peptidoglycan synthesized by PBP $2 \mathrm{x} / \mathrm{FtsW}$ and/or function to strengthen the primary cell wall before it is exposed to turgor pressure and the external milieu. Since there are three different class A PBPs, it is possible that they together serve both functions. Further studies are required to confirm or reject these ideas.

\section{Materials and Methods}

All data, strains, oligonucleotides, and experimental procedures used in this study are provided in the main article and SI Appendix.

Cultivation and Transformation of Bacteria. All strains used in the present study are listed in SI Appendix, Table S1. Escherichia coli was grown in Luria Bertani (LB) broth or on LB agar plates at $37^{\circ} \mathrm{C}$ containing ampicillin $\left(100 \mu \mathrm{g} \mathrm{mL}^{-1}\right)$ when necessary. Liquid cultures were grown aerobically with shaking. Chemically competent $E$. coli cells were transformed by heat shocking at $42{ }^{\circ} \mathrm{C}$. S. pneumoniae was grown in liquid $\mathrm{C}$ medium (46) or on Todd-Hewitt (TH) agar plates (BD Difco) at $37{ }^{\circ} \mathrm{C}$. When grown on $\mathrm{TH}$ agar the cells were incubated in a sealed container made anaerobically $\left(<1 \% \mathrm{O}_{2}\right)$ by including AnaeroGen sachets from Oxoid. Transformation of $S$. pneumoniae was done by adding CSP-1 (final concentration of $250 \mathrm{ng} \mathrm{mL}^{-1}$ ) and the transforming DNA (50 to $100 \mathrm{ng}$ ) to $1 \mathrm{~mL}$ of exponentially growing cells at $\mathrm{OD}_{550}=0.05$ Following incubation at $37^{\circ} \mathrm{C}$ for $2 \mathrm{~h}$, transformants were selected by plating $30 \mu \mathrm{L}$ of cell culture on $\mathrm{TH}$ agar plates containing the appropriate antibiotic: kanamycin $\left(400 \mu \mathrm{g} \mathrm{mL}^{-1}\right)$, streptomycin $\left(200 \mu \mathrm{g} \mathrm{mL}^{-1}\right)$, or spectinomycin $\left(200 \mu \mathrm{g} \mathrm{mL}^{-1}\right)$.

Depletion of FtsW and PBP2x. During cultivation of strains css12 and SPH163, ectopic expression of FtsW and PBP2x was maintained by the addition of $0.2 \mu \mathrm{M}$ of Coms to the growth medium. ComS is a peptide pheromone consisting of seven amino acids (LPYFAGC). Exogenous peptide pheromone is internalized by the native Ami oligopeptide permease. In the cytoplasm it directly interacts with and activates the constitutively expressed ComR transcriptional activator. In the activated state ComR binds to its cognate comX promoter, which has been engineered to drive the ectopic expression of FtsW (strain css12) and PBP2x (strain SPH163). In depleted cells the Coms peptide is removed from the medium by replacing ComS-containing medium with ComS-free medium. The ComRS system originates from Streptococcus thermophilus, where it regulates competence for natural transformation. See Berg et al. for further details $(8,23)$.

Immunodetection of FtsW-3xFlag. A C-terminally 3xFlag-tagged version of FtsW (FtsW-3xFlag) was ectopically expressed using the ComRS system (strain gs1709). Depletion of FtsW-3xFlag was performed as described above in $5 \mathrm{~mL}$ cultures. Parallel cultures induced with $0.2 \mu \mathrm{M}$ Coms were used as controls. When the level of FtsW-3xFlag was reduced to a concentration rendering the cells immune to CbpD-B6, the cells were harvested at $4,000 \times \mathrm{g}$. Cell lysates were prepared for sodium dodecyl sulfate-polyacrylamide gel electrophoresis (SDS-PAGE) and immunodetected as previously described (47). The anti-Flag antibody (F7425, Sigma-Aldrich) used to detect FtsW-3xFlag was diluted 1:4,000.

DNA Cloning. All primers used in this study are listed in SI Appendix, Table S2. To construct pRSET-cbpD-B6, the $c b p D-B 6$ gene from $S$. mitis B6 was amplified from genomic DNA using the primer pair so1/so2. The gene was amplified without the signal sequence encoding part, starting from codon 41 . The $c b p D-B 6$ amplicon was cleaved with $X b a l$ and HindIII and ligated into pRSET A 
(Invitrogen), generating pRSET-cbpD-B6. The plasmid pRSET-sfGFP-cbpD-B6 was constructed by substituting the CHAP encoding part (amino acids 41 to $175)$ of $c b p D-B 6$ with the $s f-g f p$ gene. The $s f-g f p$ gene was amplified using the kp116 and kp119 primers and SPH370 genomic DNA as a template, and the $c b p D-B 6-\Delta c h a p$ gene was amplified from $S 07$ genomic DNA using the primer pair kp117/kp118. Using overlap extension PCR and the primers $\mathrm{kp} 116$ and kp117, sf-gfp was fused to $c b p D-B 6-\Delta c h a p$. The resulting $s f-g f p-$ $c b p D-B 6$ amplicon was cleaved with Ndel and Hindlll and ligated into PRSET $A$, giving the PRSET-sfGFP-cbpD-B6 plasmid.

Amplicons used to transform $S$. pneumoniae were constructed by overlap extension PCR as previously described by Johnsborg et al. (48). We employed the Janus cassette (49) to knock out genes and to introduce recombinant DNA at desired positions in the $S$. pneumoniae genome. When substituting the native $p b p 2 x$ gene with a low-affinity version ( $p b p 2 x$-exB6), an additional version of the native gene was ectopically expressed during transformation using the ComRS system as described by Berg et al. (23). The spectinomycin-resistant marker aad9 was employed to knock out lytA in strain ds789.

Expression and Purification of CbpD-B6. E. coli BL21 containing PRSET-cbpD$B 6$ was grown to $\mathrm{OD}_{550}=0.4$ to 0.5 at $37^{\circ} \mathrm{C}$. Then production of $\mathrm{CbpD}-\mathrm{B} 6$ was induced by adding a final concentration of $0.1 \mathrm{mM}$ isopropyl $\beta$-D-1thiogalactopyranoside (IPTG) followed by incubation at $20^{\circ} \mathrm{C}$ for $4 \mathrm{~h}$. The cells were harvested at 5,000 $\times \mathrm{g}$ for $5 \mathrm{~min}$ and resuspended in 1/100 culture volume of Tris-buffered saline (TBS) at pH 7.4. The cells were lysed using the Fast Prep method with $\leq 106 \mu \mathrm{m}$ glass beads at $6.5 \mathrm{~m} \mathrm{~s}^{-1}$, and insoluble material was removed by centrifugation at 20,000 $\times \mathrm{g}$. CbpD-B6 was purified from the soluble protein fraction by performing DEAE cellulose chromatography as described by Sanchez-Puelles et al. (20), but using TBS (pH 7.4) instead of a phosphate buffer $(\mathrm{pH} 7.0)$. To remove choline from the eluted CbpD-B6 protein, it was dialyzed against TBS (pH 7.4) for $1 \mathrm{~h}$ at room temperature. After concentrating the dialyzed protein to a final volume of $500 \mu \mathrm{L}$ using an Amicon centrifugal filter (10,000 MW), it was further purified by gel filtration through a Superdex $7510 / 300 \mathrm{GL}$ column (GE Healthcare) at a flow rate of $0.3 \mathrm{~mL} \mathrm{~min}^{-1}$ in TBS ( $\mathrm{pH} 7.4$ ).

CbpD-B6 Resistance Assay. Pneumococcal cells were grown in 96-well microtiter plates, and $\mathrm{OD}_{550}$ was measured every $5 \mathrm{~min}$. When reaching $\mathrm{OD}_{550}=0.2$ oxacillin was added in concentrations decreasing from $100 \mu \mathrm{g} \mathrm{mL}^{-1}$ down to $0.003 \mu \mathrm{g} \mathrm{mL}^{-1}$ in a twofold dilution series. Cells with zero antibiotic added were used as controls. In some cases, $10 \mu \mathrm{g} \mathrm{mL}^{-1}$ of moenomycin were added together with oxacillin. The cells were grown for $10 \mathrm{~min}$ in the presence of antibiotics before purified CbpD-B6 was added to a final concentration of $5 \mu \mathrm{g} \mathrm{mL} \mathrm{m}^{-1}$. CbpD-sensitive cells were observed as a drop in $\mathrm{OD}_{550}$. For the time kinetic experiments, oxacillin $\left(0.8 \mu \mathrm{g} \mathrm{mL}^{-1}\right)$ was added simultaneously with 11 parallel cell cultures grown in a 96-well microtiter plate. Then CbpD-B6

1. A. L. Lovering, S. S. Safadi, N. C. J. Strynadka, Structural perspective of peptidoglycan biosynthesis and assembly. Annu. Rev. Biochem. 81, 451-478 (2012)

2. W. Vollmer, D. Blanot, M. A. de Pedro, Peptidoglycan structure and architecture FEMS Microbiol. Rev. 32, 149-167 (2008).

3. O. Massidda, L. Nováková, W. Vollmer, From models to pathogens: How much have we learned about Streptococcus pneumoniae cell division? Environ. Microbiol. 15, 3133-3157 (2013).

4. E. Sauvage, F. Kerff, M. Terrak, J. A. Ayala, P. Charlier, The penicillin-binding proteins: Structure and role in peptidoglycan biosynthesis. FEMS Microbiol. Rev. 32, 234-258 (2008).

5. H. T. Tsui et al., Pbp2x localizes separately from $\mathrm{Pbp} 2 \mathrm{~b}$ and other peptidoglycan synthesis proteins during later stages of cell division of Streptococcus pneumoniae D39. Mol. Microbiol. 94, 21-40 (2014).

6. C. M. Kell et al., Deletion analysis of the essentiality of penicillin-binding proteins $1 \mathrm{~A}$ 2B and 2X of Streptococcus pneumoniae. FEMS Microbiol. Lett. 106, 171-175 (1993)

7. J. Paik, I. Kern, R. Lurz, R. Hakenbeck, Mutational analysis of the Streptococcus pneumoniae bimodular class A penicillin-binding proteins. J. Bacteriol. 181, 3852 3856 (1999).

8. K. H. Berg, G. A. Stamsås, D. Straume, L. S. Håvarstein, Effects of low PBP2b levels on cell morphology and peptidoglycan composition in Streptococcus pneumoniae R6. J. Bacteriol. 195, 4342-4354 (2013).

9. A. J. Meeske et al., SEDS proteins are a widespread family of bacterial cell wall polymerases. Nature 537, 634-638 (2016)

10. H. Cho et al., Bacterial cell wall biogenesis is mediated by SEDS and PBP polymerase families functioning semi-autonomously. Nat. Microbiol. 1, 16172 (2016).

11. A. Taguchi et al., FtsW is a peptidoglycan polymerase that is functional only in complex with its cognate penicillin-binding protein. Nat. Microbiol. 4, 587-594 (2019).

12. L. T. Sham et al., Bacterial cell wall. MurJ is the flippase of lipid-linked precursors for peptidoglycan biogenesis. Science 345, 220-222 (2014).
( $1 \mu \mathrm{g} \mathrm{mL}^{-1}$ ) was added to the first well at time 0 , then to the second well after $1 \mathrm{~min}$ and so on for $10 \mathrm{~min}$.

Microscopy. For TEM and SEM analyses, strain RH425 was grown to $\mathrm{OD}_{550}=$ 0.2 , and CbpD-B6 was added to a final concentration of $0.5 \mu \mathrm{g} \mathrm{mL}^{-1}$. The enzyme was allowed to attack the cells for $1 \mathrm{~min}$ at $37{ }^{\circ} \mathrm{C}$ before they were fixed in a mixture of $2 \%\left(v v^{-1}\right)$ formaldehyde and $2.5 \%$ volume-volume ratio $\left(v v^{-1}\right)$ glutaraldehyde. The cells were fixed on ice for $1 \mathrm{~h}$ and then prepared for SEM and TEM imaging as previously described by Straume et al. (50). RH425 cells grown for $2 \mathrm{~h}$ (from $\mathrm{OD}_{550}=0.1$ to $\mathrm{OD}_{550}=0.4$ ) with $0.4 \mu \mathrm{g} \mathrm{mL}^{-1}$ moenomycin or $0.1 \mu \mathrm{g} \mathrm{mL}^{-1}$ oxacillin and SPH157 cells depleted for PBP2b [as described by Berg et al. (8)] were fixed and prepared for electron microscopy in the same way.

To determine the binding pattern of CbpD-B6 on sensitive and immune $S$. pneumoniae cells, a $10 \mathrm{~mL}$ cell culture of $S$. pneumoniae was split in two when reaching $O D_{550}=0.2$. One half was left untreated, while oxacillin was added to the other half to a final concentration of $0.8 \mu \mathrm{g} \mathrm{mL}^{-1}$. Both cultures were incubated further for $10 \mathrm{~min}$ at $37{ }^{\circ} \mathrm{C}$ before formaldehyde was added to a final concentration of $2.5 \%$. Both nontreated and oxacillin-treated cells were fixed on ice for $1 \mathrm{~h}$. The fixed cells were washed three times in 1/5 volume of phosphate-buffered saline (PBS), before sfGFP-CbpD-B6 (purified as described for CbpD-B6) was bound to the cell surface as described by Eldholm et al. (16). Briefly, $100 \mu \mathrm{L}$ of cells were applied to a microscope glass slide (inside a hydrophobic frame made with a PAP pen), and cells were immobilized by incubation at room temperature for $5 \mathrm{~min}$. Nonbound cells were rinsed off the glass by PBS. Cells were then incubated in $100 \mu \mathrm{L}$ PBS containing $0.05 \%$ Tween 20 and $15 \mu \mathrm{g} \mathrm{mL}{ }^{-1}$ sfGFP-CbpD-B6 for $8 \mathrm{~min}$ at room temperature. Nonbound sfGFP-CbpD-B6 was washed off the cells by rinsing the glass slide by submerging the glass slide in five tubes each containing $40 \mathrm{~mL}$ of PBS. Phase contrast pictures and GFP fluorescence pictures were captured using a Zeiss AxioObserver with an ORCA-Flash4.0 V2 Digital CMOS camera (Hamamatsu Photonics) through a 100× PC objective. An HPX 120 Illuminator was used as a light source for fluorescence microscopy. Phase contrast pictures of FtsW-depleted cells were captured as described above. Images were prepared in ImageJ.

Statistical Analysis. To determine the relationship between reduction in $\mathrm{OD}_{550}$ and minutes of oxacillin treatment (Fig. 4), the following sixth-order equation was used: $y=-0.0047 x^{6}+0.1661 x^{5}-2.2897 x^{4}+14.975 x^{3}-43.815 x^{2}+$ $28.423 x+66.23$. The experiment was repeated three times, and the data are presented as mean \pm SD.

ACKNOWLEDGMENTS. This work was supported by grants from the Research Council of Norway (Grants No. 240058 and 250976) and the Norwegian University of Life Sciences. The work in Spain was supported by a grant from the Spanish Ministry of Science, Innovation and Universities (BFU2017-90030-P to J.A.H.).

13. T. Mohammadi et al., Identification of FtsW as a transporter of lipid-linked cell wall precursors across the membrane. EMBO J. 30, 1425-1432 (2011).

14. S. Leclercq et al., Interplay between penicillin-binding proteins and SEDS proteins promotes bacterial cell wall synthesis. Sci. Rep. 7, 43306 (2017).

15. D. C. McPherson, D. L. Popham, Peptidoglycan synthesis in the absence of class A penicillin-binding proteins in Bacillus subtilis. J. Bacteriol. 185, 1423-1431 (2003).

16. V. Eldholm et al., Pneumococcal CbpD is a murein hydrolase that requires a dual cell envelope binding specificity to kill target cells during fratricide. Mol. Microbiol. 76, 905-917 (2010).

17. D. Straume, G. A. Stamsås, L. S. Håvarstein, Natural transformation and genome evolution in Streptococcus pneumoniae. Infect. Genet. Evol. 33, 371-380 (2015).

18. S. Layec, B. Decaris, N. Leblond-Bourget, Characterization of proteins belonging to the CHAP-related superfamily within the Firmicutes. J. Mol. Microbiol. Biotechnol. 14, 31-40 (2008).

19. I. Pérez-Dorado, S. Galan-Bartual, J. A. Hermoso, Pneumococcal surface proteins: When the whole is greater than the sum of its parts. Mol. Oral Microbiol. 27, 221-245 (2012).

20. J. M. Sanchez-Puelles, J. M. Sanz, J. L. Garcia, E. Garcia, Immobilization and single-step purification of fusion proteins using DEAE-cellulose. Eur. J. Biochem. 203, 153-159 (1992).

21. O. Kocaoglu, H. C. T. Tsui, M. E. Winkler, E. E. Carlson, Profiling of $\beta$-lactam selectivity for penicillin-binding proteins in Streptococcus pneumoniae D39. Antimicrob. Agents Chemother. 59, 3548-3555 (2015).

22. J. Sauerbier, P. Maurer, M. Rieger, R. Hakenbeck, Streptococcus pneumoniae R6 interspecies transformation: Genetic analysis of penicillin resistance determinants and genome-wide recombination events. Mol. Microbiol. 86, 692-706 (2012).

23. K. H. Berg, T. J. Biørnstad, D. Straume, L. S. Håvarstein, Peptide-regulated gene depletion system developed for use in Streptococcus pneumoniae. J. Bacteriol. 193, 5207-5215 (2011).

24. M. Schlag et al., Role of staphylococcal wall teichoic acid in targeting the major autolysin Atl. Mol. Microbiol. 75, 864-873 (2010). 
25. G. A. Stamsås et al., Identification of EloR (Spr1851) as a regulator of cell elongation in Streptococcus pneumoniae. Mol. Microbiol. 105, 954-967 (2017).

26. C. Morlot, A. Zapun, O. Dideberg, T. Vernet, Growth and division of Streptococcus pneumoniae: Localization of the high molecular weight penicillin-binding proteins during the cell cycle. Mol. Microbiol. 50, 845-855 (2003).

27. A. D. Land et al., Requirement of essential Pbp2x and GpsB for septal ring closure in Streptococcus pneumoniae D39. Mol. Microbiol. 90, 939-955 (2013).

28. D. Pérez-Núñez et al., A new morphogenesis pathway in bacteria: Unbalanced activity of cell wall synthesis machineries leads to coccus-to-rod transition and filamentation in ovococci. Mol. Microbiol. 79, 759-771 (2011).

29. X. Liu et al., High-throughput CRISPRi phenotyping identifies new essential genes in Streptococcus pneumoniae. Mol. Syst. Biol. 13, 931 (2017).

30. H. C. T. Tsui et al., Suppression of a deletion mutation in the gene encoding essentia PBP2b reveals a new lytic transglycosylase involved in peripheral peptidoglycan synthesis in Streptococcus pneumoniae D39. Mol. Microbiol. 100, 1039-1065 (2016)

31. J. J. Zheng, A. J. Perez, H. T. Tsui, O. Massidda, M. E. Winkler, Absence of the KhpA and KhpB (JAG/EloR) RNA-binding proteins suppresses the requirement for PBP2b by overproduction of FtsA in Streptococcus pneumoniae D39. Mol. Microbiol. 106, 793814 (2017).

32. A. K. Fenton, L. El Mortaji, D. T. C. Lau, D. Z. Rudner, T. G. Bernhardt, CozE is a member of the MreCD complex that directs cell elongation in Streptococcus pneumoniae. Nat. Microbiol. 2, 16237 (2016)

33. B. E. Rued et al., Suppression and synthetic-lethal genetic relationships of $\Delta g p s B$ mutations indicate that GpsB mediates protein phosphorylation and penicillin-binding protein interactions in Streptococcus pneumoniae D39. Mol. Microbiol. 103, 931957 (2017).

34. A. K. Fenton et al., Phosphorylation-dependent activation of the cell wall synthase PBP2a in Streptococcus pneumoniae by MacP. Proc. Natl. Acad. Sci. U.S.A. 115, 2812 2817 (2018).

35. P. Mitkowski et al., Structural bases of peptidoglycan recognition by lysostaphin SH3b domain. Sci. Rep. 9, 5965 (2019).

36. A. Fiser, S. R. Filipe, A. Tomasz, Cell wall branches, penicillin resistance and the secrets of the MurM protein. Trends Microbiol. 11, 547-553 (2003).

37. W. Vollmer, A. Tomasz, The pgdA gene encodes for a peptidoglycan $\mathrm{N}$-acetylglucosamine deacetylase in Streptococcus pneumoniae. J. Biol. Chem. 275, 20496-20501 (2000).
38. M. I. Crisóstomo et al., Attenuation of penicillin resistance in a peptidoglycan O-acety transferase mutant of Streptococcus pneumoniae. Mol. Microbiol. 61, 1497-1509 (2006).

39. A. Vigouroux et al., Cell-wall synthases contribute to bacterial cell-envelope integrity by actively repairing defects. bioRxiv: $10.1101 / 763508$ (12 September 2019).

40. P. Demchick, A. L. Koch, The permeability of the wall fabric of Escherichia coli and Bacillus subtilis. J. Bacteriol. 178, 768-773 (1996).

41. Y. G. Santin, E. Cascales, Domestication of a housekeeping transglycosylase for assembly of a type VI secretion system. EMBO Rep. 18, 138-149 (2017).

42. E. M. Scheurwater, L. L. Burrows, Maintaining network security: How macromolecula structures cross the peptidoglycan layer. FEMS Microbiol. Lett. 318, 1-9 (2011).

43. T. Carter et al., The type IVa pilus machinery is recruited to sites of future cell division mBio 8, e02103-16 (2017).

44. H. C. T. Tsui, S. K. Keen, L. T. Sham, K. J. Wayne, M. E. Winkler, Dynamic distribution of the SecA and SecY translocase subunits and septal localization of the HtrA surface chaperone/protease during Streptococcus pneumoniae D39 cell division. mBio 2 e00202-11 (2011).

45. S. Brega, E. Caliot, P. Trieu-Cuot, S. Dramsi, SecA localization and SecA-dependent secretion occurs at new division septa in group B Streptococcus. PLoS One 8, e65832 (2013).

46. S. Lacks, R. D. Hotchkiss, A study of the genetic material determining an enzyme in Pneumococcus. Biochim. Biophys. Acta 39, 508-518 (1960).

47. G. A. Stamsås, D. Straume, Z. Salehian, L. S. Håvarstein, Evidence that pneumococca WalK is regulated by StkP through protein-protein interaction. Microbiology 163 , 383-399 (2017).

48. O. Johnsborg, V. Eldholm, M. L. Bjørnstad, L. S. Håvarstein, A predatory mechanism dramatically increases the efficiency of lateral gene transfer in Streptococcus pneumoniae and related commensal species. Mol. Microbiol. 69, 245-253 (2008).

49. C. K. Sung, H. Li, J. P. Claverys, D. A. Morrison, An rpsL cassette, janus, for gene re placement through negative selection in Streptococcus pneumoniae. Appl. Environ. Microbiol. 67, 5190-5196 (2001).

50. D. Straume, G. A. Stamsås, Z. Salehian, L. S. Håvarstein, Overexpression of the fratricide immunity protein ComM leads to growth inhibition and morphological abnormalities in Streptococcus pneumoniae. Microbiology 163, 9-21 (2017). 